Revista Destaques Acadêmicos, Lajeado, v. 8, n. 3, 2016. ISSN 2176-3070 DOI: http://dx.doi.org/10.22410/issn.2176-3070.v8i3a2016.1153 www.univates.br/revistas

\title{
ALEITAMENTO MATERNO: ABORDAGEM GRUPAL DO PET-SAÚDE EM UM GRUPO DE GESTANTES COM BASE NO CÍRCULO DE CULTURA DE PAULO FREIRE
}

\author{
Josefa Alves de Andrade ${ }^{1}$, Leidy Dayane Paiva de Abreu², \\ Juliana Domingos Melo ${ }^{3}$, Maria Adelane Monteiro da Silva ${ }^{4}$, \\ Ana Hirley Rodrigues Magalhães ${ }^{5}$, Raquel Xavier Guimarães ${ }^{6}$, \\ Gislanny Rodrigues Oliveira ${ }^{7}$, Glícia Mesquita Martiniano Mendonça ${ }^{8}$
}

Resumo: O presente trabalho tem como objetivo descrever a abordagem grupal realizada por acadêmicos e extensionistas Pet-Saúde acerca do aleitamento materno para um grupo de gestantes de um Centro de Saúde da Família do bairro Dom Expedito, Sobral/CE. Para tanto, fora realizada uma pesquisa participante por meio de uma abordagem grupal no grupo de gestantes para levantamento do conhecimento das gestantes e lactantes sobre as culturas e mitos do aleitamento materno. As ações

1 Profissional de Educação Física. Especialista em Caráter de Residência Multiprofissional em Saúde Mental pela Escola de Formação em Saúde da Família Visconde de Sabóia (EFSFVS), Sobral/CE. E-mail: jjosefaandrade@hotmail.com.

2 Enfermeira, Mestrando do Programa Cuidados Clínicos em Enfermagem e Saúde da Universidade Estadual do Ceará (UECE), Fortaleza-CE. E-mail: dayannepaiva@hotmail.com.

3 Acadêmica de Odontologia pela Universidade Federal do Ceará (UFC), Campus Sobral/CE. E-mail: july_dmel@hotmail.com

4 Enfermeira, Professora Doutora em Enfermagem. Docente do Curso de Enfermagem da Universidade Estadual Vale do Acaraú (UVA), Sobral-CE. E-mail: adelanemonteiro@hotmail.com.

5 Enfermeira, Mestranda da Rede Nordeste de Formação em Saúde da Família da Universidade Estadual Vale do Acaraú - UVA (Nucleadora), Sobral-CE. E-mail: ana_magalhaes@hotmail.com.

6 Enfermeira, Mestranda da Rede Nordeste de Formação em Saúde da Família da Universidade Estadual Vale do Acaraú - UVA (Nucleadora), Sobral-CE. E-mail: raquelguimaraesponte@hotmail.com.

7 Enfermeira da Universidade Estadual Vale do Acaraú (UVA), Sobral-CE. E-mail: gislannyoliveira@hotmail.com.

8 Enfermeira, Mestranda do Programa Cuidados Clínicos em Enfermagem e Saúde da Universidade Estadual do Ceará (UECE), Fortaleza-CE. E-mail: glicia_martiniano@hotmial.com. 
relacionadas à promoção do aleitamento materno devem não somente ser incentivadas, mas pensadas enquanto estratégias que (re)conheçam o sentido da amamentação para as mulheres e (re)considerem a ordem de importância das vantagens de amamentar e que suas dúvidas sejam esclarecidas.

Palavras-chave: Aleitamento Materno. Gestantes. Educação em Saúde.

\section{INTRODUÇÃO}

As questões relacionadas à prática da amamentação têm-se configurado objeto de interesse para diferentes autores e grupos sociais ao longo da história. Em todas as épocas, o ser humano foi levado a construir rotas alternativas para responder à demanda das mulheres que, por opção ou imposição, trilharam o caminho do desmame precoce (ALMEIDA, 1999).

Devido aos seus benefícios nutricionais, psicológicos, econômicos, imunológicos e fisiológicos, a amamentação é indicada pela Organização Mundial da Saúde como a atitude mais eficiente para o desenvolvimento adequado de uma criança no primeiro ano de vida, (OMS, 1994). A lactação é um processo natural, um momento em que a mãe e o bebê estarão se conhecendo, aprendendo e interagindo.

Dentre os diversos elementos que se relacionam direta ou indiretamente com a amamentação, a mesma pode ser influenciada por questões econômicas, sociais e culturais. Dentre as questões culturais, os tabus ou restrições alimentares, nem sempre justificáveis do ponto de vista biológico, podem fazer com que a lactante se prive de nutrientes importantes para o seu sustento e, consequentemente, para a produção de leite. Sendo assim, torna-se fundamental avaliar o comportamento e conhecimento de gestantes sobre a amamentação.

A partir dessa visão de atenção integral à saúde da mulher sobre o aleitamento materno, entende-se que o primeiro passo para o uso e aprimoramento de tecnologias capazes de promover essa saúde integral constitui-se de uma etapa de informações para gestantes sobre a importância do leite materno e seus benefícios. Esse processo envolve o levantamento da situação e conhecimento das mesmas e iniciativas já existentes, a avaliação da viabilidade local para a implementação das atividades, assim como as expectativas da clientela.

De acordo com Buss (2002), os profissionais que tem interesse em aperfeiçoar suas práticas em direção à promoção da saúde, para esse público alvo, devem procurar adotar abordagens metodológicas e tecnológicas enquanto meios complementares as demais intervenções de saúde. Etimologicamente o termo tecnologia deriva de "tecno" que vem de techné, que significa o saber fazer, e "logia" que vem de logos, razão, dessa forma, o termo é definido como a razão do saber fazer (CORREA, 1999). Trata-se de um conjunto de ações (concretas e abstratas) desenvolvidas com a finalidade do cuidado em saúde, envolvendo, portanto, saberes e habilidades na sua construção. 
Considerada uma tecnologia, as atividades de educação em saúde realizadas em grupos permitem o favorecimento ao apoio mútuo, o compartilhamento das dificuldades comuns vivenciadas por pessoas em situações semelhantes, o aprendizado e a adoção/manutenção de comportamentos saudáveis (MONTEIRO, 2009). As atividades educativas em grupos são dinâmicas e fazem uso de tecnologias leves, como a tecnologia do diálogo, acolhimento e escuta. A liberdade dos diálogos em um grupo proporciona resultados satisfatórios, com estabelecimento de vínculos e troca de saberes acerca dos temas de interesse para comunidade. O grupo, apesar de ser um conjunto de pessoas, não é simplesmente a soma dos participantes, o que significa que qualquer mudança que ocorra em um dos participantes vai interferir no estado do grupo como um todo. E por estarmos sempre mudando é que o grupo é dinâmico e todos são coparticipantes (ABREU et al., 2013).

Portanto, acadêmicos de enfermagem, educação física e odontologia, guiados por essa perspectiva de abordagem grupal e motivados pela recomendação do Ministério da Saúde e do Protocolo de Atenção Integral à Saúde da Gestante e da Puérpera de Baixo Risco de Sobral-CE, de 2012 a 2013, foi desenvolvida uma pesquisa com o Grupo de Gestantes do bairro Dom Expedito, Sobral-CE. Contando com a participação multidisciplinar dos profissionais da Estratégia Saúde da Família e os alunos monitores do Programa de Educação para o Trabalho em Saúde (Pet-Saúde).

O Programa Nacional de Reorientação da Formação Profissional em Saúde (Pró-Saúde) e o Programa de Educação pelo Trabalho para a Saúde (PetSaúde) são a materialização dos preceitos constitucionais contidos no Artigo 200 da Carta Magna Brasileira de 1988 que prevê a formação de recursos humanos na área de saúde, e no artigo 27 da Lei Orgânica da Saúde (Lei 8.080/1990), em que além da organização de um sistema de formação de recursos humanos prevê que os serviços públicos que integram o Sistema Único de Saúde (SUS) constituam campo de prática para ensino e pesquisa (BRASIL, 2012).

Essa investigação contribui para ampliar o entendimento dos profissionais da área da saúde no que se refere à percepção de gestantes a respeito dos mitos, tabus e restrições da amamentação, utilizando uma abordagem coletiva. Para tanto, esse artigo tem o objetivo de relatar a abordagem grupal realizada por acadêmicos e extensionistas Pet-Saúde acerca do aleitamento materno com um grupo de gestantes de um Centro de Saúde da Família do bairro Dom Expedito, Sobral/CE. A atividade forneceu subsídios às participantes sobre a importância da amamentação, com direcionamento à promoção da saúde, detendo-se no diálogo como tecnologia leve de educação em saúde.

\section{METODOLOGIA}

Pesquisa participante de abordagem qualitativa. A abordagem grupal foi realizada, por acadêmicos e extensionistas Pet-Saúde dos cursos de 
Enfermagem, Educação Física da Universidade Estadual Vale do Acaraú, e do curso de Odontologia da Universidade Federal do Ceará, assim como preceptores do Pet-Saúde e equipe multidisciplinar, no ano de 2013.

O tema aleitamento materno foi abordado com um grupo de gestantes atendidas no Centro de Saúde da Família (CSF) Maria Eglantine Pontes Guimarães do bairro Dom Expedito, Sobral/CE, local onde as mesmas realizavam seu pré-natal. A atividade contou com o apoio de um facilitador, cuja intervenção foi sendo reduzida no decorrer dos diálogos à medida que a interação entre os membros do grupo aumentava.

As ações de extensão foram orientadas pelo referencial teórico de "Círculos de Cultura" de Paulo Freire, o qual baseia-se em trocas de conhecimentos e experiências como meio do aprendizado (FREIRE, 2011). $\mathrm{O}$ círculo permite aos participantes e pesquisadores elaborar processos de conhecimento e ação a partir de suas reais necessidades e, em conjunto, articular alternativas para resolvê-las, facilitando o processo de cuidado (BRANDÃO, 2005). Para isso, adotaram-se os seguintes passos:

Levantamento de informações: $O$ primeiro encontro foi destinado a conhecer o funcionamento do CSF, rotina, dias e horários. Foi realizada uma conversa prévia com os profissionais de saúde, quando foram apresentados os objetivos da atividade de educação em saúde no serviço. Por meio de conversa informal, os mesmos explicitaram a necessidade de abordar o tema aleitamento materno com o grupo de gestantes, devido ao elevado número de casos identificados no bairro de baixa adesão à amamentação exclusiva até os seis meses de idade do bebê.

Planejamento: Primeiramente, acompanhamos durante um mês as consultas de pré-natal realizadas pelos enfermeiros com as gestantes, momento em que foram registradas as experiências e impressões sobre a atividade em roteiro de observação e diário de campo. A partir da análise prévia dos dados, confirmou-se a necessidade de abordar a temática aleitamento materno para o melhor conhecimento das futuras mamães sobre a importância do mesmo e a desmitificação que existe acerca do assunto, buscando orientar acerca dos benefícios do aleitamento materno.

Execução: Para a problematização das temáticas utilizaram-se dinâmicas e texto-base, além de manter a escuta ativa e atitude de valorização das gestantes. Cada encontro foi organizado para contemplar três momentos acolhimento, desenvolvimento e avaliação, com o intuito de promover práticas educativas voltadas à promoção da saúde, possibilitando a aproximação, interação e diálogo entre o conhecimento técnico e o popular.

Avaliação: Foi realizada a cada encontro de acordo com as impressões das participantes. A seguir descreve-se detalhadamente cada etapa nesse processo de implantação e desenvolvimento do grupo de gestantes. 


\section{ANÁLISE E DISCUSSÕES DOS RESULTADOS}

Os resultados da pesquisa foram dispostos nas seguintes etapas: levantamento de informações, planejamento, implementação e avaliação.

\section{Levantamento de informações e planejamento da intervenção}

Para o planejamento da intervenção foi necessário, antes de tudo, conhecer a realidade do grupo de gestantes do CSF do bairro Dom Expedito. Interagir com elas foi fundamental para identificar seus conhecimentos, medos, tabus e dúvidas acerca do aleitamento materno. Além disso, foram coletadas informações como: idade; estado civil; grau de instrução; renda familiar; situação conjugal; número de filhos; dados obstétricos, como a data da primeira menstruação, primeira relação sexual, data provável do parto, número de gestações e de consultas pré-natais. O levantamento dessas informações possibilitou a emergência de subsídios essenciais ao planejamento e intervenção junto ao grupo. Para facilitar o entendimento quanto aos dados coletados nesta fase, dividiram-se as informações em categorias, a saber: dados gerais e obstétricos e sentimentos e conhecimentos acerca da amamentação.

\section{Execução da atividade educativa}

Participaram da abordagem grupal 25 gestantes. A média de idade fora de aproximadamente 23 anos, variando entre 15-35 anos. Dentre as entrevistadas dez (10) tinham ensino fundamental incompleto, duas (02) ensino fundamental completo, sete (07) ensino médio incompleto e seis (06) ensino médio completo. A intervenção foi realizada em um único momento, o qual está descrito no quadro (1) a seguir: 
Quadro 1 - Demonstrativo das atividades e técnicas utilizadas na sessão educativa junto às gestantes do grupo, Sobral, 2013

\begin{tabular}{|c|c|c|c|}
\hline \multirow{4}{*}{ Sessão } & Atividades Desenvolvidas & Metodologia / técnica & Objetivos esperados \\
\hline & Acolhimento & $\begin{array}{l}\text { Técnica de apresentação } \\
\text { dos participantes em } \\
\text { grupo: “Dinâmica de } \\
\text { Interação de Grupo" }\end{array}$ & $\begin{array}{l}\text { Proporcionar às } \\
\text { participantes o } \\
\text { conhecimento mútuo; } \\
\text { Demonstrar que nenhum } \\
\text { membro do grupo pode } \\
\text { passar despercebido. }\end{array}$ \\
\hline & $\begin{array}{l}\text { Desenvolvimento: } \\
\text { Discussão sobre } \\
\text { aleitamento materno. } \\
\text { (Compartilhamento, } \\
\text { oferecimento de } \\
\text { informações e } \\
\text { aprendizagem). }\end{array}$ & $\begin{array}{l}\text { Apresentação em forma } \\
\text { de círculo de cultura sobre } \\
\text { os temas: Vantagens para } \\
\text { mãe e o bebê; Durante } \\
\text { a mamada; Não existe } \\
\text { leite fraco; Posições e } \\
\text { pegadas; e Dificuldades na } \\
\text { amamentação. }\end{array}$ & $\begin{array}{l}\text { Proporcionar o } \\
\text { compartilhamento de } \\
\text { conhecimentos sobre } \\
\text { aleitamento materno entre } \\
\text { gestantes e pesquisadoras. }\end{array}$ \\
\hline & $\begin{array}{l}\text { Encerramento: Avaliação } \\
\text { da Sessão-Dinâmica. }\end{array}$ & $\begin{array}{l}\text { Técnica de avaliação- } \\
\text { Dinâmica "Papel } \\
\text { Amassado" }\end{array}$ & \begin{tabular}{|l|} 
Levar as participantes \\
a refletir sobre seu \\
aprendizado e a avaliar a \\
experiência vivenciada, o \\
quanto foi válida e o que \\
agregou de novo.
\end{tabular} \\
\hline
\end{tabular}

O desenvolvimento da intervenção fundamentada na pedagogia de Paulo Freire possibilitou às gestantes a participação ativa nas ações de saúde, uma vez que este arcabouço teórico traz como premissa a valorização do diálogo e favorece o reconhecimento das usuárias enquanto sujeitos portadores de saberes sobre o processo saúde-doença-cuidado, evitando o monólogo de palestras onde se busca apenas transferir conhecimentos. No âmbito da educação em saúde, os círculos de cultura podem ser uma ferramenta fundamental de atuação por possibilitar a troca entre conhecimento técnico e popular, permitindo o desenvolvimento de ações de prevenção e controle de doenças (PADILHA, 2003).

De acordo com Freire (2011), os Círculos de Cultura são espaços em que dialogicamente se ensina e se aprende, em que se produz conhecimento no lugar da justaposição ou da superposição de conhecimentos feitas pelo educador sobre o educando e onde se constroem novas hipóteses de leitura do mundo. Ou seja, é um lugar onde todos têm a palavra, onde todos leem e escrevem o mundo. É um espaço de trabalho, pesquisa, exposição de prática, dinâmicas e vivências que possibilitam a construção coletiva do conhecimento (SPIGOLON, 2009). 
No Círculo de Cultura realizado com as gestantes foram destacadas as temáticas sobre as vantagens para a mãe e o bebê; durante a mamada; não existe leite fraco; posicionamento e pegada e dificuldades na amamentação. A seguir estão descritas as atividades desenvolvidas em cada momento das sessões, de forma a compreender o que ocorreu no processo grupal.

Objetivos da sessão: Proporcionar aos participantes do grupo que se conheçam e promover o compartilhamento de conhecimentos sobre Aleitamento Materno. Participantes que estavam presentes nesse encontro: Flor 1; Flor 2; Flor 3; Flor 4; Flor 5; Flor 6...Flor 25.

Acolhimento: utilizou-se a "Dinâmica de Interação de Grupos" que tem como objetivo proporcionar às participantes o conhecimento mútuo, além de demonstrar que nenhum membro pode passar despercebido. Nesta dinâmica, uma das facilitadoras solicitou às participantes a formação de subgrupos com dois parceiros desconhecidos. Durante de 6 a 7 minutos, as integrantes dos subgrupos entrevistam-se mutuamente. Após, voltaram ao grupo e cada uma fez a apresentação da parceira. Todos deveriam permanecer atentos e verificar se a sua apresentação foi feita de forma correta, em acordo aos dados fornecidos. A seguir, o facilitador pediu às participantes que se manifestassem sobre a apresentação feita pela colega e sobre o valor do exercício. A partir dessa dinâmica, pôde-se perceber que o clima ficou descontraído e familiar, podendo-se iniciar as ações no grupo.

Desenvolvimento: no primeiro momento da ação foi utilizada uma pergunta norteadora: "O que vocês sabem sobre aleitamento materno?". As respostas foram dispostas em um cartaz colocado à parede para descrever o conhecimento que as gestantes tinham acerca do aleitamento materno, considerando que a maioria (12) eram primigestas. As palavras usadas pelas gestantes para caracterizar o aleitamento materno foram: "É forte", "Demonstração de carinho e amor", "Faz bem para o bebê", "Ajuda a perder peso", "Evita que o bebê tenha diarreia". Após esse resultado, iniciou-se a abordagem sobre os temas mais relevantes sobre o aleitamento materno.

$\mathrm{O}$ primeiro tópico abordado junto às gestantes foi "Vantagens do aleitamento para a mãe", sendo relatada a perda de peso. A seguir, a facilitadora do grupo abordou o tema "As vantagens do aleitamento para o bebê". Nessa temática as opiniões das participantes foram significativas e relevantes, com destaque para o estabelecimento de um relacionamento afetivo entre a mãe e o bebê, a prevenção de diarreias e o crescimento e fortalecimento do bebê.

Foram utilizados slides que continham as informações a serem discutidas, sendo estimulada a participação das gestantes no decorrer de todo o encontro. No início as gestantes ficaram receosas em participar do grupo. Porém, com o passar do tempo, a interação entre elas e os estudantes foi ocorrendo e todas começaram a participar, sendo possível demonstrar as posições corretas para amamentar nas próprias gestantes. 
O tópico "Durante a mamada" abordou como deve transcorrer a mamada, quando foi dialogado sobre a importância da mamada completa e os nutrientes que o leite materno fornece em cada estágio da mesma. $\mathrm{O}$ tópico seguinte traz o esclarecimento sobre os mitos existentes acerca do leite materno, com o tema "Não existe leite fraco". Neste a facilitadora esclareceu que o leite materno fornece os nutrientes necessários ao crescimento do bebê independente das particularidades de cada mãe. A participação das gestantes foi crucial para a realização desse encontro, e principalmente, para que este obtivesse resultado positivo.

No tópico seguinte, a abordagem esteve relacionada ao posicionamento do bebê para a correta pega da aréola materna durante a amamentação. Houve a participação de uma gestante que, voluntariamente, demonstrou como deve ser a posição correta. A participante estava na quarta gestação e já havia integrado o grupo em gestação anterior e pode, dessa forma, contribuir para o aprendizado das demais gestantes. Ela fez a demonstração com o auxílio de uma prótese de mama, de borracha, e com um boneco, simulando o bebê. Com isso, o clima entre as participantes ficou descontraído e todas as mães puderam participaram, expressando suas opiniões e dúvidas. Sentir o envolvimento das gestantes na atividade foi bastante satisfatório para as facilitadoras do grupo.

A abordagem sobre as "Dificuldades na Amamentação" fez com que as gestantes também participassem do encontro, pois a temática se referia as principais dificuldades encontradas pela mãe para a realização da amamentação, como as fissuras no mamilo e o ingurgitamento de mama. Os cuidados em relação à prevenção e ao tratamento de fissuras foram debatidos e o uso da massagem mamária foi sugerido para evitar o endurecimento das mamas. As falas a seguir retratam a preocupação das gestantes com essas questões:

"Tenho medo que minha mama crie fissura." (Flor 3).

"Quando veio meu primeiro filho, meu leite ingurgitou, espero que agora não aconteça mais" (Flor 10).

Ao término das atividades, os estudantes oportunizaram um espaço aberto para que outras dúvidas e questionamentos pudessem ser feitos pelas gestantes. Nesse momento, uma gestante relatou que seu mamilo é plano e por isso sentia medo de não conseguir amamentar. Os facilitadores aproveitaram a oportunidade para explicar como deve ser a pega do bebê na mama nesta condição, utilizando, para isso, um álbum seriado do Ministério da Saúde.

Todas as mulheres têm possibilidades fisiológicas de amamentar, porém, esse potencial inato não assegura a ocorrência da amamentação. O desmame precoce dificulta a prática do aleitamento materno exclusivo até os seis meses. Muitas mulheres, embora considerem o leite materno a melhor opção para alimentar a criança, não a amamentam. Mesmo aquelas que participam da rotina assistencial, estabelecida pela política estatal como base para o êxito na amamentação, costumam desmamar seus filhos antes do quarto mês de vida. 
Apesar de as mães valorizarem o leite materno, elas não se sentem seguras a ponto de adotá-lo como único alimento durante o período em que ele é indicado (ARAUJO; ALMEIDA, 2007).

Aí está a importância de incentivar essas mulheres para que realizem a amamentação exclusiva e a abordagem grupal é uma excelente estratégia para que esse envolvimento realmente ocorra, já que o tema foi discutido sob forma de diálogo e as dúvidas forma sanadas. Nesta abordagem, houve o estabelecimento de vínculo entre facilitadores e gestantes e o reforço de que todas elas são capazes de realizar a amamentação a partir do conhecimento sobre sua importância e dos benefícios para ambos, mãe e bebê.

Encerramento: para finalizar a sessão, as facilitadoras utilizaram uma dinâmica de avaliação denominada "Papel amassado". Para isso, foram utilizados pedaços de papel em branco e a música "Como uma Onda", de autoria do cantor Lulu Santos. A dinâmica descontraiu as gestantes e a avalição foi positiva, conforme será relatado a seguir.

\section{Avaliação}

A avaliação das atividades aconteceu no encerramento do grupo de gestantes. Cada participante recebeu um papel, que foi amassado por elas, e em seguida foi pedido para que todas desamassassem o papel e o deixasse como estava antes. A dinâmica buscou demonstrar que, por mais que as participantes tentassem desamassar, o papel não seria mais o mesmo, assim como elas após a realização da atividade. Esta tem por objetivo levar os participantes a refletir sobre seu aprendizado e avaliar a experiência vivida, o quanto foi válida e o que agregou de novo aos conhecimentos prévios. Para que as gestantes verbalizassem sua avaliação, foi-lhes pedido que respondessem a seguinte questão: $O$ que as gestantes entenderam sobre a dinâmica? E qual a importância da atividade realizada acerca do aleitamento materno?

Nas falas, as participantes relataram estar satisfeitas com as atividades, pois integraram-se e divertiram-se, e ressaltaram que as informações sobre o tema foram importantes para que ocorra o aleitamento exclusivo conforme o recomendado. Algumas relataram ter tirado dúvidas sobre a importância, vantagens do aleitamento materno e as técnicas de como amamentar. Como descritas abaixo:

"Não sabia que a amamentação previne contra infecções na criança" (Flor 04).

"O leite materno pelo que aprendi hoje só traz vantagens para mim e a criança" (Flor 03).

"Agora eu sei como dá mama, com todas essas técnicas de como me posicionar e o meu bebê, tirei minhas dúvidas" (Flor 01).

O leite materno é o melhor e mais completo alimento para o bebê, especialmente nos primeiros seis meses de vida, e nenhum outro alimento 
pode substituí-lo com vantagem. Além de se constituir num gesto de amor, o aleitamento materno proporciona segurança afetiva à criança e oferece inúmeras vantagens para ambos, mãe e filho, uma vez que a criança amamentada no seio raramente adoece (WHO, 2003).

Ao serem indagadas sobre a atividade educativa em saúde realizada no CSF, todas a consideram de fundamental importância, pois as dúvidas foram esclarecidas, assim como medos e anseios acerca da temática.

"Gostei demais de tudo, vou sair com outra visão sobre amamentar" (Flor 12).

"Espero que no PSF aconteça momentos como esses para tirar nossas dúvidas e medos" (Flor 08).

\section{CONSIDERAÇÕES FINAIS}

A atividade educativa em forma de Círculo de Cultura mostrou-se adequada à abordagem do tema aleitamento materno em grupos de gestantes na Atenção Básica. Implementar ações educacionais, especificamente com temáticas que tragam subsídios às gestantes, reforça a necessidade da mãe pensar no bem-estar do seu bebê e dela própria.

Diante disto, torna-se fundamental aliar informação, discussão e orientação, no sentido de proporcionar às gestantes esclarecimentos de dúvidas, medos e preocupações com relação ao aleitamento materno. Com o desenvolvimento das atividades foi possível promover maior interação entre o conhecimento técnico e o popular, por meio da pedagogia de Paulo Freire, possibilitando a aproximação das acadêmicas facilitadoras com a realidade das gestantes.

Trabalhar o grupo de gestantes a partir das rodas de cultura constituiuse em um espaço de socialização de vivências e conhecimentos, sendo uma oportunidade para as gestantes expressarem seus medos, dúvidas, ansiedades e sentimentos, como também para relacionar-se com outras pessoas que estão vivenciando o mesmo processo, o que possibilita um melhor enfrentamento das mudanças e situações que envolvem a período gravídico.

Na realização da presente pesquisa, pode-se identificar que muitas dúvidas foram esclarecidas para gestantes acerca do aleitamento materno, principalmente para primigestas, uma vez que estas participantes tinham mais dúvidas e anseios acerca da amamentação.

Espera-se que os resultados dessa abordagem contribuam para o desenvolvimento de ações de promoção e apoio à amamentação no grupo de gestantes, tendo em vista seu importante papel para a adoção e manutenção do aleitamento materno. Reforçando a ideia de que as ações de promoção do aleitamento materno desenvolvidas por equipes de CSF devem ser rotineiras, para que possa ser capaz de vencer as barreiras sociais, informar sobre a 
temática, superar os mitos e tabus, e, verdadeiramente, contribuir para a prática da amamentação.

Diante disso, as ações relacionadas à promoção do aleitamento materno devem não somente ser incentivadas, mas pensadas enquanto estratégias que (re)conheçam o sentido da amamentação para as mulheres e (re)considerem a ordem de importância das vantagens de amamentar e que suas dúvidas sejam esclarecidas.

A pesquisa trouxe às estudantes significativas experiências, tanto no âmbito do ensino quanto na pesquisa e o envolvimento dos acadêmicos do PetSaúde com os profissionais do serviço contribuiu para reforçar a importância da atuação interdisciplinar em saúde.

\section{REFERÊNCIAS}

ABREU et al. Abordagem educativa utilizando os Círculos de Cultura de Paulo Freire: experiência de acadêmicos de enfermagem no "Grupo Adolescer". Adolesc. Saude, Rio de Janeiro, v. 10, n. 4, p. 66-70, out/dez 2013.

ALMEIDA, J.A.G. Amamentação: um híbrido natureza-cultura. Rio de Janeiro: FIOCRUZ; 1999.

ARAÚJO, R.M.A; ALMEIDA, J.A.G. Aleitamento materno: o desafio de compreender a vivência. Revista de Nutrição. Campinas: 2007; 20(4), p. 431-438.

BRANDÃO, Carlos Rodrigues. O que é educação. São Paulo: Brasiliense, 2005.

BRASIL. Ministério da Saúde. Conselho Nacional de Saúde. Comissão Nacional de Ética em Pesquisa - CONEP. Resolução ${ }^{\circ}{ }^{4}$ 466/12: sobre pesquisas envolvendo seres humanos. Brasília, 2012.

BUSS, P.M. Promoção da Saúde da Família. Revista Brasileira de Saúde da Família. 2(6): 50-63, 2002.

CORREA, M.B. Tecnologia, In: CATTANI, A.D. (org). Trabalho e Tecnologia: dicionário crítico. 2a ed. Petrópolis (RJ): Vozes; 1999. p. 251-57.

FREIRE P. Educação como prática da liberdade. 27 ed. Rio de Janeiro: Paz e Terra; 2011.

MONTEIRO, M.A.A. Abordagem Grupal para Promoção da Saúde de Famílias com Recém-Nascidos Hospitalizados [tese]. Sobral: Universidade Federal do Ceará, 2009.

OMS. Organização Mundial da Saúde. Lactação. In: Organização Mundial da Saúde (OMS) Alimentação infantil bases fisiológicas. São Paulo (SP): IBFAN Brasil e Instituto de Saúde, OMS, OPAS e UNICEF Brasil; 1994. p.17-35. 
PADILHA, P.R. Currículo intertranscultural: por uma escola curiosa, prazerosa e aprendente. Tese de Doutorado em Educação - Faculdade de Educação, Universidade de São Paulo, 2003.

SPIGOLON, N.I. Pedagogia da Convivência: Elza Freire - uma vida que faz Educação. 2009. 264 f. Dissertação (Mestrado em Educação) - Programa de PósGraduação, Universidade Estadual de Campinas - UNICAMP, Campinas, 2009.

WHO. World Health Organization. Global strategy for infant and young child feeding, 2003, 14-15. 